\title{
Microscopic Change in Hardened Cement Paste due to High-Speed Impact
}

\author{
Yuya Sakai $^{{ }^{*}}$, Ivwananji Sikombe $^{2}$, Keiko Watanabe $^{3}$ and Hiroyuki Inoue ${ }^{4}$
}

\begin{abstract}
Impact load was applied to hardened cement paste (HCP) specimens using a gas gun to investigate microscopic changes in the specimens and develop a better response model of concrete subjected to impact load. Plasma emission was observed at the moment of impact at 420 metres per second and the colour of the portion near the impact point turned brighter. This brighter portion was analysed, and it was observed that the pore structure was coarser compared to the other portion. However, the results of thermogravimetry and X-ray diffraction analysis were similar. A possible reason is that the generated heat was instantaneous and the rate of the temperature increase in the HCP decreased due to evaporation of water in the HCP. These results indicate that during impact at a few hundred metres per second, porosity increase due to heat effect is more dominant than porosity decrease due to mechanical compaction.
\end{abstract}

\section{Introduction}

Concrete is used in a variety of structures and thus, subjected to a wide range of loads and impact loading. Relatively low-speed impacts often occur due to collisions from vehicles and rocks (Tsang and Lam 2008; Prochowski 2010; Lambert and Nicot 2013). Middle speed impacts also occur due to hurricanes and explosions produced by flying objects (Minor 1994; Ning et al. 2007; Pulson 1994), while high speed impacts occur due to gunshots and missiles (Kennedy 1976; Vossoughi et al. 2007; Gomez and Shukla 2001). Moon exploration has attracted increasing interest (Gent 2018) and concrete is one of the promising material for the construction of a lunar base (Happel 1993; Lin et al. 1989). Since there is no atmosphere on the moon, space debris reaches the moon surface and the velocity of space debris can be ten times faster than that of a bullet (Roybal et al. 1999; Klinkrad 2006). Therefore, concrete may be subjected to very high-speed impact in the near future. Various types of experiments have been conducted, from low-speed impact to very-high speed impact, to investigate the fracture patterns of concrete subjected to impact load,

${ }^{1}$ Assistant Professor, Institute of Industrial Science, The University of Tokyo, 4-6-1 Komaba, Meguro, Tokyo 153-8505, Japan.

*Corresponding author, E-mail: ysakai@iis.u-tokyo.ac.jp

${ }^{2}$ Master course student, Institute of Industrial Science, The University of Tokyo, 4-6-1 Komaba, Meguro, Tokyo 153-8505, Japan.

${ }^{3}$ Professor, College of Science and Engineering, Ritsumeikan University, 1-1-1 Noji-Higashi, Kusatsu, Shiga 525-8577, Japan.

${ }^{4}$ Professor, Institute of Industrial Science, The University of Tokyo, 4-6-1 Komaba, Meguro, Tokyo 153-8505, Japan. and results have shown that concrete exhibits various fracture patterns and responses depending on the property and velocity of the projectile as well as the concrete strength. Kennedy (1976) classified the fracture patterns of concrete into the following seven categories: (a) penetration, (b) cone cracking and plugging, (c) spalling, (d) radial cracking associated with (i) the proximal face and (ii) the distal face, (e) scabbing, (f) perforation, and (g) overall structural responses and failures. Li et al. (2005) summarized various models applied to calculate the response of concrete subjected to impact loading. It is clear from the above review papers that macroscopic damage occurs in concrete due to impact load. However, microscopic damage or property change due to impact load has not been thoroughly investigated.

The stress condition induced by impact load can be simulated by the triaxial test. Gran and Frew (1997) conducted an impact test using a rocket bomb of $2.3 \mathrm{~kg}$ flying at $315 \mathrm{~m} / \mathrm{s}$, which induced triaxial stress greater than $150 \mathrm{MPa}$ in the concrete. After their experiment, a triaxial test was conducted at a confining pressure of up to $400 \mathrm{MPa}$ to investigate the response of concrete subjected to impact load, and the stress-strain curves (Malecot et al. 2010) and the effects of aggregates (Vu et al. 2011; Poinard et al. 2012), moisture content (Vu et al. 2009), and so forth were reported. Sakai et al. (2016) conducted a triaxial test on hardened cement paste (HCP) and reported that the porosity of HCP decreased after the test. In the numerical simulation of impact test using concrete, reduction in the porosity is considered an important parameter for accurate simulation (Burlion et al. 2000; Shiu et al. 2008). However, it has not been experimentally determined whether the property change of HCP due to impact load can be reproduced by the triaxial test. This should be clarified before conducting a triaxial test to simulate the response of concrete subjected to impact. 
Table 1 Chemical components of cement.

\begin{tabular}{|c|c|c|c|c|c|c|c|c|c|}
\hline Ig. Loss & Insol. & $\mathrm{SiO}_{2}$ & $\mathrm{Al}_{2} \mathrm{O}_{3}$ & $\mathrm{Fe}_{2} \mathrm{O}_{3}$ & $\mathrm{CaO}$ & $\mathrm{MgO}$ & $\mathrm{SO}_{3}$ & $\mathrm{Na}_{2} \mathrm{O}$ & $\mathrm{K}_{2} \mathrm{O}$ \\
\hline 2.64 & 0.06 & 20.27 & 5.30 & 2.95 & 64.8 & 0.95 & 1.74 & 0.28 & 0.45 \\
\hline
\end{tabular}

Ren et al. (2013) carried out scanning electron microscope (SEM) observation and X-Ray diffraction (XRD) analysis on ultra-high performance concrete after impact by a projectile of approximately $14 \mathrm{~g}$ flying at 914 $\mathrm{m} / \mathrm{s}$. They reported a high-pressure and high-temperature phase of silica and pointed out that the high temperature was generated due to the impact. However, their study focused on the bonding between fiber and cement paste matrix. The authors recommended that to produce concrete with high resistance against impact, a material that does not undergo crystalline transformation should be used. They also highlighted the possibility that water in concrete evaporated due to heat generated by the impact and the vapor induced damage to the concrete. As a result, the authors also recommended the use of materials that melt easily to prepare an escape route for the vapor. As it is well-known that an impact generates heat (Rao et al. 2016; Johnston et al. 2017), the phase and pore structure of HCP may change and it is inappropriate to conduct a triaxial test to simulate the response of concrete due to impact load without considering the effect of heat.

In this study, impact test was conducted using HCP to investigate the microscopic property change and to determine whether the same change observed in HCP in the triaxial test occurs in the impact test. To investigate the change in cement paste due to impact load, the test should be conducted using HCP and not concrete because it is difficult to separate the change in the cement paste and that in the aggregate. Therefore, understanding microscopic changes in HCP due to impact load will be helpful in developing a more realistic concrete simulation model.

\section{Experimental Method}

\subsection{Specimen}

This study used HCP with water to cement ratio of 0.4. Tables 1 and 2 present the properties of ordinary Portland cement. The paste was first mixed for $30 \mathrm{~s}$ at low speed (orbital rotation: $62 \pm 5 \mathrm{rpm}$, planetary rotation: $140 \pm 5 \mathrm{rpm}$ ). The mixer was stopped for $30 \mathrm{~s}$ to $60 \mathrm{~s}$ to scrap off cement paste on the mixing bowl and paddle. The mixer was then set to high speed (orbital rotation: $125 \pm 5 \mathrm{rpm}$, planetary rotation: $284 \pm 5 \mathrm{rpm}$ ) and allowed to run for $60 \mathrm{~s}$. The mixed paste was cast into 100 $\mathrm{mm}$ diameter $\times 100 \mathrm{~mm}$ height cylindrical moulds and sealed. The HCP was demoulded $24 \mathrm{~h}$ after casting, kept under water at $20^{\circ} \mathrm{C}$ for 8 months, and sealed in plastic bags until testing.

\subsection{Impact test procedure}

A vertical single-stage diaphragmless gas gun was used for the impact test. In an ordinary gas gun, a projectile is launched by the breaking of a diaphragm due to gas
Table 2 Physical properties of cement.

\begin{tabular}{|c|c|}
\hline Density & Specific surface area \\
\hline $\mathrm{g} / \mathrm{cm}^{3}$ & $\mathrm{~cm}^{2} / \mathrm{g}$ \\
\hline 3.15 & 3510 \\
\hline
\end{tabular}

pressure, and the fragments of the diaphragm fly and hit the target (Wegener et al. 2000; Togami et al.2004). The gun used in this study does not employ a diaphragm. Therefore, the effect of flying pieces of the diaphragm is eliminated. The outlook of the gun is shown in Fig. 1. The projectile was launched from a pressure vessel through a launch tube and impacted the specimen in a test chamber. The specimen was confined with a set of steel molds, which can be separated into four pieces as shown in Fig. 2. The confinement was prepared to reduce scattering of the specimen pieces due to the impact so that the sample used for the analysis can be collected. The projectile is shown in Fig. 3. The impactor is a hemispherical brass one with a radius of $7 \mathrm{~mm}$, while the sabot is made of polyethylene. The mass of the projectile was $16 \mathrm{~g}$ including a neodymium magnet inside it. The magnet induces electromotive force when it passes through some coils placed at the exit of the launch tube to determine the velocity of the projectile from the time lag of the electromotive force. The collision was recorded using a high-speed camera (Phantom v711, Vision Research Inc., NJ, USA). The projectiles were launched four times. The velocity of two of the projectiles was 200 $\mathrm{m} / \mathrm{s}$, while that of the other projectiles was $420 \mathrm{~m} / \mathrm{s}$.

\subsection{Observation with optical microscope}

The non-tested specimen and pieces of the tested specimens were impregnated with a two-component

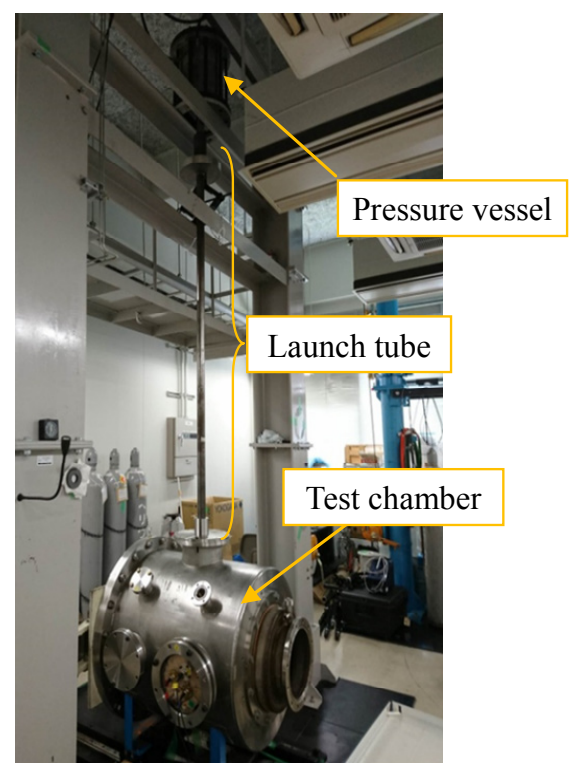

Fig. 1 Diaphragmless vertical gas gun. 
epoxy resin (room-temperature curing). Then, a thin section with thickness of $30 \mu \mathrm{m}$ was prepared from the tested specimen and observed using a polarization microscope (ECLIPSE LV100N POL, Nikon, Tokyo, Japan).

\subsection{Mercury intrusion porosimetry (MIP)}

The pore size distribution of the samples was analyzed using MIP (POREMASTER 60GT, Quantachrome, Florida, USA). The tested and non-tested specimens were crushed into cubes with edges measuring $5 \mathrm{~mm}$ and these were immersed in acetone for $24 \mathrm{~h}$. Subsequently, the cubes were dried using the D-dry method (Zhang and Scherer 2011) for $24 \mathrm{~h}$ and $1 \mathrm{~g}$ of the cubes was used for MIP analysis. In MIP analysis, the contact angle between the sample and mercury was assumed to be $130^{\circ}$ and the surface tension of mercury was assumed to be $0.48 \mathrm{~N} / \mathrm{m}$. The applied pressure was from $0.15 \mathrm{MPa}$ to $131 \mathrm{MPa}$, corresponding to pore diameters of $8400 \mathrm{~nm}$ and $9.4 \mathrm{~nm}$, respectively.

\subsection{Thermal gravimetric (TG) analysis and X-Ray diffraction analysis}

TG analysis was carried out using TG-DTA (EXSTAR 6000 , Seiko Instruments) to analyze the thermal property of the HCP. Pieces of the samples were taken from the tested and non-tested specimens, crushed into powder, and sieved using a $150 \mu \mathrm{m}$ sieve. Approximately $10 \mathrm{mg}$ of each sample was collected, and TG analysis was carried out. The sample was heated up to $1000^{\circ} \mathrm{C}$ at the rate of $20^{\circ} \mathrm{C} / \mathrm{min}$ in nitrogen atmosphere.

$\mathrm{XRD}$ analysis was carried out to investigate the

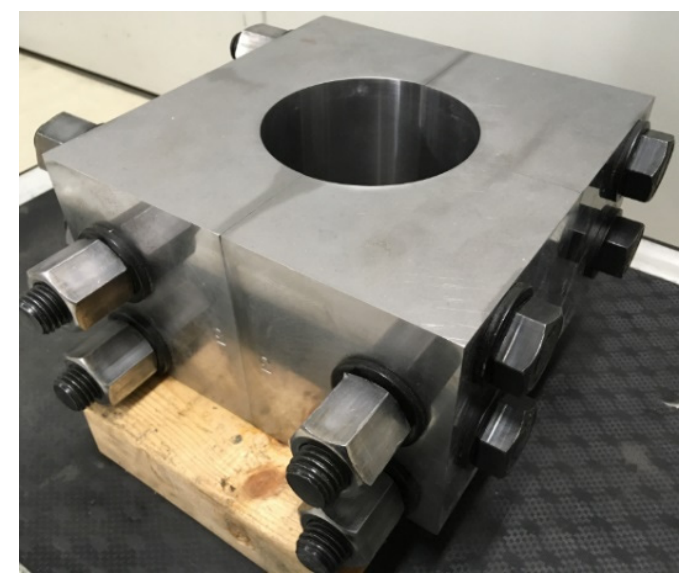

Fig. 2 Steel molds for sample confinement.

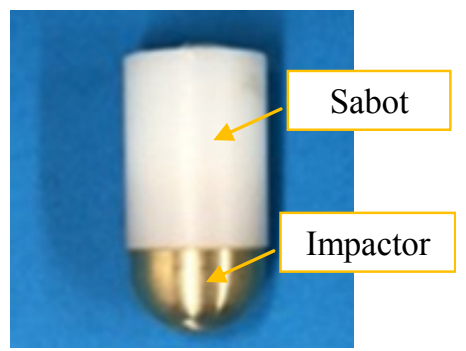

Fig. 3 Projectile. change in the crystalline phase due to the impact. Multiflex (Rigaku, Tokyo, Japan) was used and the measurement conditions was, X-ray source: $\mathrm{CuK} \alpha$ line, tube bulb voltage: $40 \mathrm{kV}$, tube bulb current: $30 \mathrm{~mA}$, divergence slit: $1 / 2^{\circ}$, scattering slit: $1 / 2^{\circ}$, scanning angle $(2 \theta): 5$ to $70^{\circ}$, scan step of the angle: $0.02 \%$. The powder sample for XRD analysis was prepared using the same procedure used for TG analysis. Since the amount of the sample was small, a zero diffraction sample holder was used.

\subsection{Preheating with laser pulse and electric furnace}

Luminescence due to plasma was observed at the impact of the projectile into the HCP, which will be explained in Section 3.1. To investigate the effect of instantaneous heating on the HCP, a non-tested specimen of $50 \times 50 \times$ $10 \mathrm{~mm}$ was heated using laser pulse. Another specimen was heated in an electric furnace at $300^{\circ} \mathrm{C}$ for $2 \mathrm{~h}$ for comparison with the laser heated specimen.

Laser heating was carried out using a YAG laser. The output was $5.9 \mathrm{~W}$, while the width and interval of the pulse were $100 \mathrm{~ns}$ and $0.1 \mathrm{~s}$, respectively. The color of the portion near the impact point turned brighter and laser pulse was repeatedly applied to HCP for $5 \mathrm{~s}$ until a similar color change was observed; this will be described in Section 3.1. The cutting surface of the color change portion is shown in Fig. 4. The color change occurred up to a depth of $3 \mathrm{~mm}$ from the surface at the center of the heating. To measure the temperature increase due to laser heating, a type-K thermocouple (Medtherm, Alabama, USA) was embedded into the cement paste plate at a depth of $5 \mathrm{~mm}$ (Fig. 5). Laser pulse was applied to the cement paste surface at the tip of the thermocouple and the temperature was measured at intervals of $5 \mu \mathrm{s}$. The measured temperature was up to $60^{\circ} \mathrm{C}$ after laser heating for $5 \mathrm{~s}$. During heating, vapor was generated from the heating point. The portion where a color change occurred was extracted and this portion was used for the analysis described above.

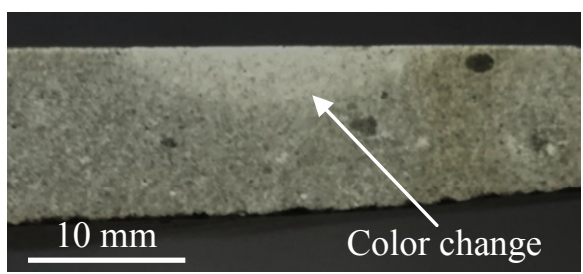

Fig. 4 Color change due to laser heating.

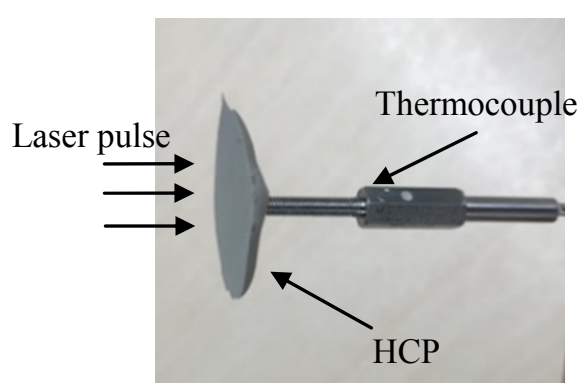

Fig. 5 Set up for temperature measurement. 


\section{Results and discussion}

\subsection{High-speed impact test}

Figure 6 shows the moment of the scatter of HCP surface due to the impact of a projectile travelling at $420 \mathrm{~m} / \mathrm{s}$. The colour of the portion near the impact point turned brighter (Fig. 7). A similar colour change was observed for the impact at $200 \mathrm{~m} / \mathrm{s}$. The cutting surface of the specimen, which was cut after the impact test and impregnated with a two-component epoxy resin, is shown in Fig. 8. The portion of the $22 \mathrm{~mm}$ depth was scattered.

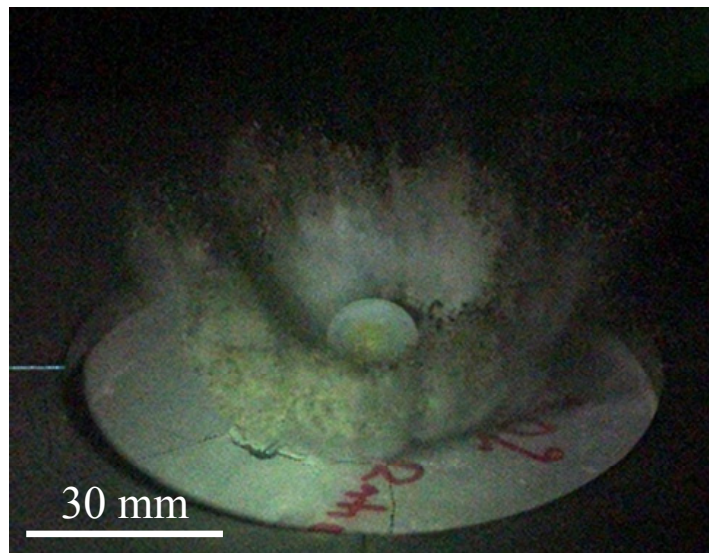

Fig. 6 Projectile hitting the sample.
The dark lines in the image are cracks filled with the intruded epoxy resin. The crack density was higher near the impact point. There is a darker portion near the impact point and this region was brighter as shown in Fig. 7. However, it turned darker because more epoxy resin intruded into the tiny cracks of this area. Figure 9(a) shows a piece of the tested sample. The brighter portion shown in the figure has a complicated shape. Figure 9(b) shows the image of the polarization microscope and the interface of the brighter and darker portions is curved. It is unlikely that mechanical stress induced such a complicated and curved interface. Therefore, another factor may have caused the colour change in HCP during impact.

Figure 10 shows the moment of the impact recorded at

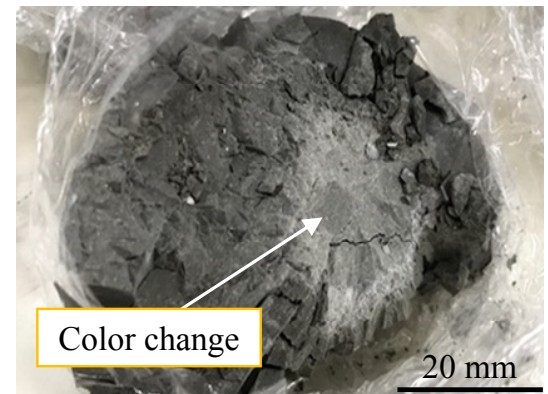

Fig. 7 Sample after the impact.

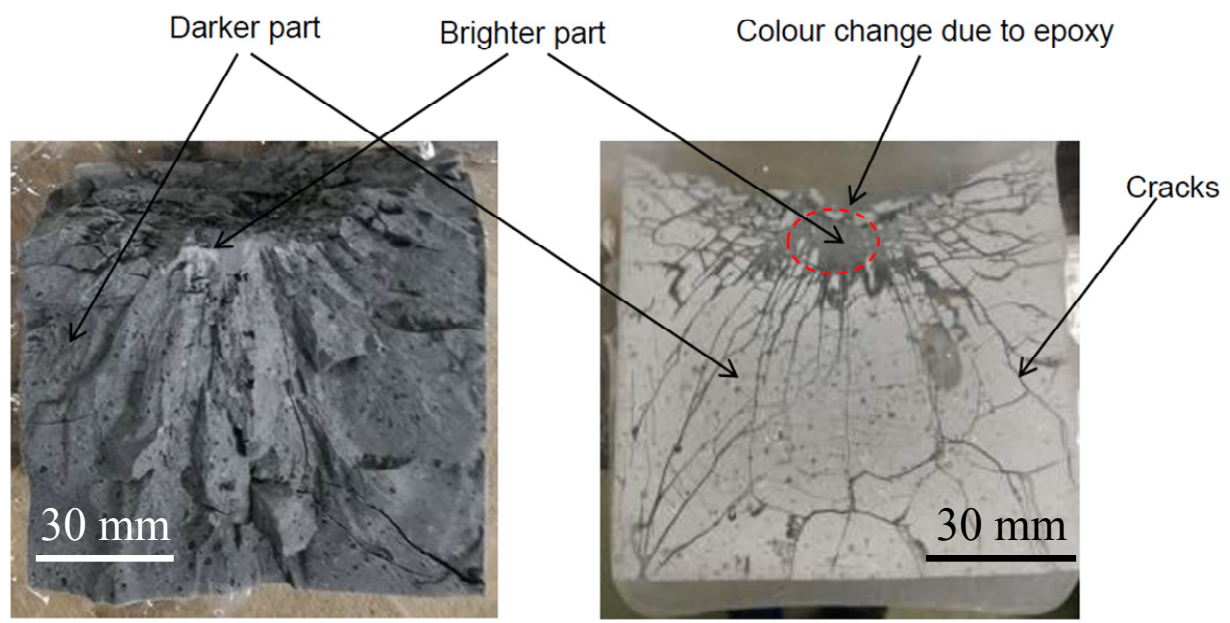

Fig. 8 Cutting surface of a whole sample after test.

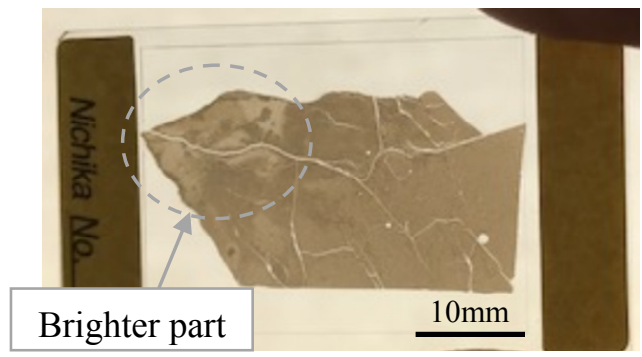

(a) Thin section

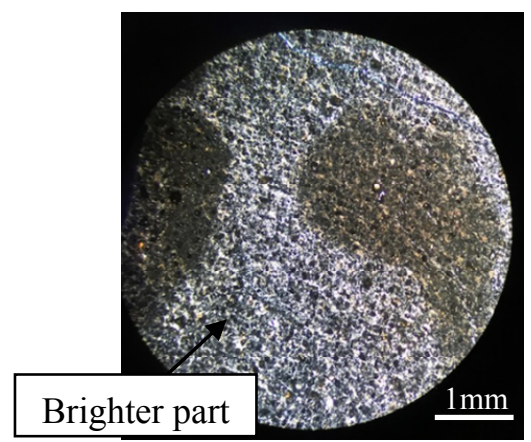

(b) Polarization microscope (crossed nicols)

Fig. 9 Cut piece of sample after test. 
a frame rate of $270000 / \mathrm{s}$ and luminescence of plasma was observed at the impact point. The generation of plasma has been observed in the impact test of other materials (Song et al. 2016; Fletcher et al. 2015). However, to the best of the authors' knowledge, this is the first time it is observed in cementitious material. Plasma is a state where an atom is ionized and decomposed into a cation and electron. Since plasma was observed in one frame and recording was done at an interval of $3.7 \mu \mathrm{s}$, plasma was emitted for a maximum of approximately $7 \mu \mathrm{s}$. In the following sections, the samples taken from a non-tested specimen and the brighter portion of the tested sample were analysed and compared. The results of the analysis on the samples heated using laser pulse and electric oven will also be presented for comparison.

\subsection{Pore size distribution}

The pore size distribution measured using MIP is shown in Fig. 11. Compared to the non-tested sample, the brighter portion taken from the tested sample had a larger pore size and volume. It has been reported that the portion near the impact point is subjected to compressive stress (Burlion et al. 2000; Shiu et al.2008). Forquin et al. (2008) reported a decrease in the air volume of mortar due to impact load. HCP also showed a smaller pore size and volume after the triaxial test (Sakai et al. 2016).

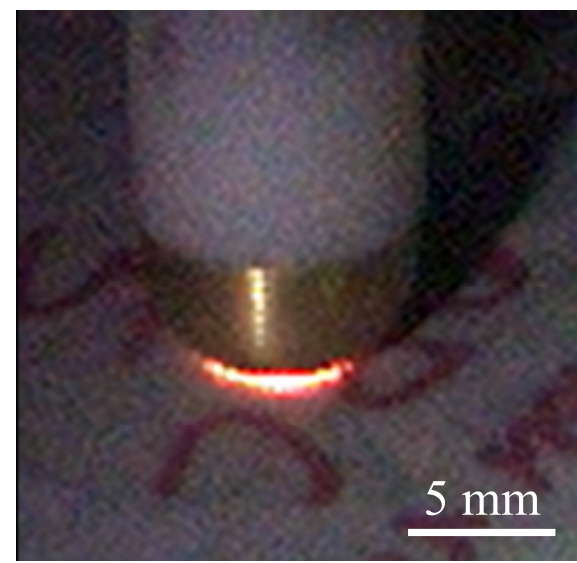

Fig. 10 Light emission at impact.

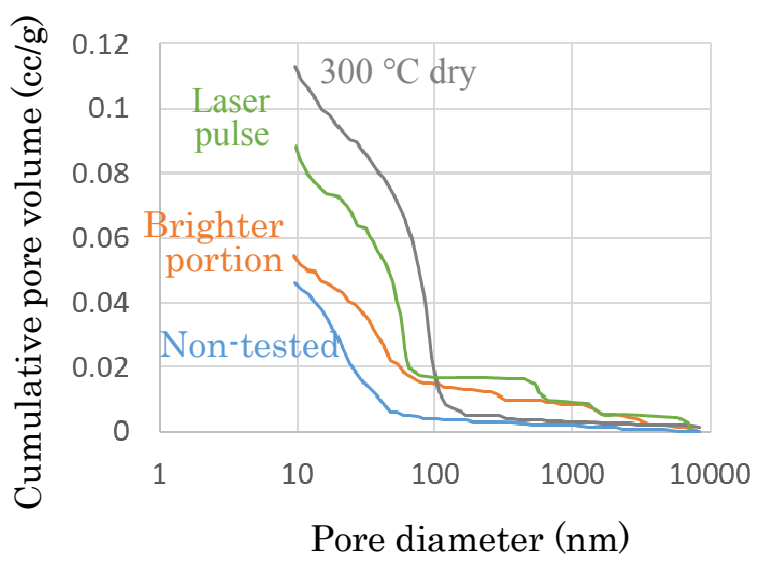

Fig. 11 Pore size distribution.
Therefore, although a similar phenomenon was expected after the impact test, the result obtained was different. This indicates that the effect of triaxial stress on cement paste matrix was not dominant during the impact test. Since plasma was observed at the impact, it is possible that the high temperature changed the pore size distribution.

However, as introduced in Section 2.6, although the laser pulse can induce high temperature and is used for metal welding (Pan et al. 2005; Ghaini et al. 2007), the temperature at which the surface of the HCP turned brighter during laser heating was $60^{\circ} \mathrm{C}$ possibly due to the suppression of the temperature increase by the evaporation of free water. Although the temperature increase due to the laser pulse is not large, as seen in Fig. 11, the pore volume and size are similar to those in the sample taken from the brighter portion for pores with diameters of $>30 \mathrm{~nm}$. Laser heating further increases the total porosity, possibly because the generated heat is higher than that caused by the impact. The result in Fig. 11 supports that the porosity change in the brighter portion is caused by heat.

\subsection{TG and XRD analysis}

The result of the thermogravimetry is shown in Fig. 12 and only a slight difference occurred between the non-tested sample and the tested sample. This result indicates that the thermal effect due to the impact did not affect the chemical properties of HCP. The result of the sample preheated at $300^{\circ} \mathrm{C}$ is also shown in Fig. 12. A small mass decrease occurred up to $300^{\circ} \mathrm{C}$ and then the curve became almost parallel with the non-tested sample. This is because the mass reduction that occurred up to $300^{\circ} \mathrm{C}$ was during preheating. The curve of the tested sample is parallel with that of the non-tested sample at temperatures higher than $150^{\circ} \mathrm{C}$ indicating that the maximum temperature that the sample experienced in the impact was $150^{\circ} \mathrm{C}$. However, unlike the sample preheated at $300^{\circ} \mathrm{C}$, the tested sample yielded a large mass reduction even when the temperature was below $150^{\circ} \mathrm{C}$. A possible reason is that the temperature increase due to the impact was instantaneous owing to cooling resulting from water evaporation. The curve of the laser heated sample is similar to that of the non-tested sample at

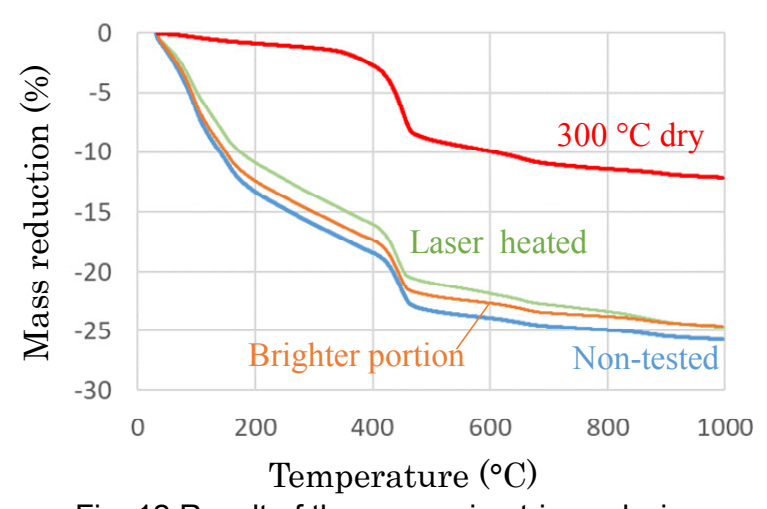

Fig. 12 Result of thermogravimetric analysis. 
temperatures higher than $100^{\circ} \mathrm{C}$. Therefore, the maximum temperature the sample experienced during laser-heating was likely approximately $100^{\circ} \mathrm{C}$. The maximum temperature indicated in Section 2.6 was lower $\left(60^{\circ} \mathrm{C}\right)$ probably because the tip of the thermocouple was not at the surface but slightly inside, while the sample for the thermogravimetry analysis was collected from the surface. Ren et al. (2013) reported that a high-temperature and high-pressure phase of $\mathrm{SiO}_{2}$ was generated. This is probably because the speed of their projectile was faster $(914 \mathrm{~m} / \mathrm{s})$ than the speed used in our study, the projectile collided with the gravel, and suppression of the rate of the temperature increase due to water evaporation was small.

The result of the XRD analysis is shown in Fig. 13 and there is no significant difference between the samples. This result indicates that a change in the molecular structure did not occur during impact and laser heating.

\subsection{Discussion on change in HCP due to impact}

The obtained results indicate that the impact resulted in plasma emission and the surface of HCP was subjected to high temperature, but the TG and XRD analyses did not yield any change. The pore volume and size, however, increased. This is probably because the instantaneous heat did not increase the temperature in HCP due to evaporation of water. The pore structure change was likely due to drying by evaporation. The pore volume and size are known to increase with drying (Suda et al. 2017; Aono et al. 2007). The colour of the portion near the impact point turned brighter and this change is likely due to the drying. The moisture content, which was calculated using the sample masses after testing and after drying at $105^{\circ} \mathrm{C}$, was $20 \%$ in a sample taken from a non-tested specimen and $10 \%$ in a sample taken from the brighter part.

In this study, HCP subjected to a projectile at $420 \mathrm{~m} / \mathrm{s}$ was analysed. However, a similar colour change due to impact on the specimen was also observed in the specimen subjected to a projectile at $200 \mathrm{~m} / \mathrm{s}$. This indicates that heat was generated, and the sample was dried even at this velocity. In the case of concrete, the rate of the temperature rise in the aggregate due to the impact can be

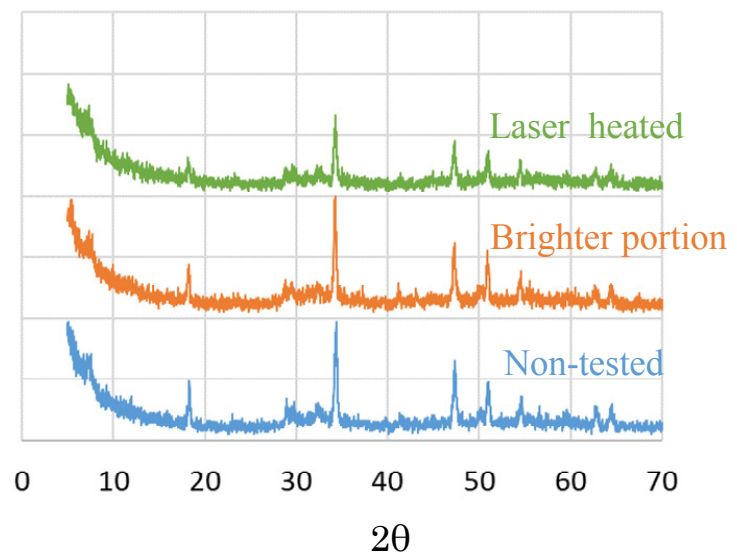

Fig. $13 \mathrm{X}$-ray diffraction analysis. higher than in the cement paste matrix due to the absence of water, which decreases the temperature rise. The reduction in the rate of the temperature rise due to evaporation possibly depends on the moisture content of the cement paste and a reduction was observed in this study because the specimen was cured under water and kept sealed until testing. As the impact speed decreases, the heat generated by the impact likely decreased and the pore volume and size in the cement paste could be reduced by the triaxial stress, as reported in a previous study (Sakai et al. 2016). The increase or decrease in the pore size and volume due to impact probably depends on the balance between the mechanical effect and heat effect. To understand the response of concrete subjected to impact load and to simulate the response with high accuracy, the condition of the increase and decrease in the pore size and volume should be investigated.

\section{Conclusions}

Researchers have conducted impact tests on concrete specimens. However, the results obtained from analysis of the specimen include information on cement paste and aggregate, which is difficult to categorize. In this study, HCP was subjected to impact load and analysed. The color near the impact point became brighter and the pore structure of this portion was coarser than that of the other portion, although the chemical properties were similar. This structural change was probably from the heat generated due to the impact, but the rate of the temperature rise due to the heat was decreased owing to evaporation of water in the HCP. The laser pulse used for metal welding was applied to the HCP; the 5 -second laser pulse increased the temperature only to $60^{\circ} \mathrm{C}$, but the laser-heated sample showed coarser pore structure than that of the non-tested sample. These results support that the instantaneous heat generated due to the impact caused the increase in pore volume and size.

In this study, the impact velocity was in the range of 200 to $420 \mathrm{~m} / \mathrm{s}$. However, a lower impact velocity can decrease the porosity as observed in the sample after the triaxial test. The relationship between the impact velocity and the pore structure should be investigated for the simulation of impact on concrete with high accuracy.

\section{Acknowledgement}

This study was financially supported by the Steel Foundation for Environmental Protection Technology. Part of this work was conducted at the Advanced Characterization Nanotechnology Platform of the University of Tokyo, supported by the Nanotechnology Platform of the Ministry of Education, Culture, Sports, Science and Technology (MEXT), Japan.

\section{References}

Aono, Y., Matsushita, F., Shibata, S. and Hama, Y., (2007). "Nano-structural changes of C-S-H in hardened cement paste during drying at $50^{\circ} \mathrm{C}$." 
Journal of Advanced Concrete Technology, 5(3), 313-323.

Burlion, N., Gatuingt, F., Pijaudier-Cabot, G. and Daudeville, L., (2000). "Compaction and tensile damage in concrete: constitutive modelling and application to dynamics." Computer Methods in Applied Mechanics and Engineering, 183(3), 291-308.

Fletcher, A., Close, S. and Mathias, D., (2015). "Simulating plasma production from hypervelocity impacts." Physics of Plasmas, 22(9), 093504.

Forquin, P., Arias, A. and Zaera, R., (2008). "Role of porosity in controlling the mechanical and impact behaviours of cement-based materials." International Journal of Impact Engineering, 35(3), 133-146.

Gent, E., (2018). "Moon bases being planned now may show us how to live off-planet [online]." USA, NBC News Digital. Available from: $<$ https://www.nbcnews. $\mathrm{com} / \mathrm{mach} / \mathrm{science} / \mathrm{moon}$-bases-being-planned-now-m ay-show-us-how-live-ncna855826> [Accessed 26 August 2019].

Ghaini, F. M., Hamedi, M., Torkamany, M. and Sabbaghzadeh, J., (2007). "Weld metal microstructural characteristics in pulsed Nd: YAG laser welding." Scripta Materialia, 56(11), 955-958.

Gomez, J. T. and Shukla, A., (2001). "Multiple impact penetration of semi-infinite concrete." International Journal of Impact Engineering, 25(10), 965-979.

Gran, J. K. and Frew, D. J., (1997). "In-target radial stress measurements from penetration experiments into concrete by ogive-nose steel projectiles." International Journal of Impact Engineering, 19(8), 715-726.

Happel, J. A., (1993). "Indigenous materials for lunar construction." Applied Mechanics Reviews, 46(6), 313-325.

Johnston, J. P., Pereira, J. M., Ruggeri, C. R. and Roberts, G. D., (2017). "High speed thermal imaging on ballistic impact of triaxially braided composites [online]." USA, National Aeronautics and Space Agency (NASA) Technical Reports Server. Available from: $<$ https://ntrs.nasa.gov/archive/nasa/casi.ntrs.nasa. gov/20170010312.pdf $>$ [Accessed 26 August 2019].

Kennedy, R. P., (1976). "A review of procedures for the analysis and design of concrete structures to resist missile impact effects." Nuclear Engineering and Design, 37(2), 183-203.

Klinkrad, H., (2006). "Space debris: models and risk analysis." Berlin, Germany: Springer-Verlag.

Lambert, S. and Nicot, S. L., (2013). "Rockfall engineering." New Jersey, USA: John Wiley \& Sons.

Li, Q. M., Reid, S. R., Wen, H. M. and Telford, A. R., (2005). "Local impact effects of hard missiles on concrete targets." International Journal of Impact Engineering, 32(1), 224-284.

Lin, T., Senseney, J. A., Arp, L. D. and Lindbergh, C., (1989). "Concrete lunar base investigation." Journal of Aerospace Engineering, 2(1), 10-19.

Malecot, Y., Daudeville, L., Dupray, F., Poinard, C. and
Buzaud, E., (2010). "Strength and damage of concrete under high triaxial loading." European Journal of Environmental and Civil Engineering, 14(6-7), 777-803.

Minor, J. E., (1994). "Windborne debris and the building envelope." Journal of Wind Engineering and Industrial Aerodynamics, 53(1), 207-227.

Ning, L., John, D. H. and Chris, W. L., (2007). "Trajectories of wind-borne debris in horizontal winds and applications to impact testing." Journal of Structural Engineering, 133(2), 274-282.

Pan, L. K., Wang, C. C., Hsiao, Y. C. and Ho, K. C., (2005). "Optimization of Nd: YAG laser welding onto magnesium alloy via Taguchi analysis." Optics and Laser Technology, 37(1), 33-42.

Poinard, C., Piotrowska, E., Malecot, Y., Daudeville, L. and Landis, E. N., (2012). "Compression triaxial behavior of concrete: the role of the mesostructure by analysis of X-ray tomographic images." European Journal of Environmental and Civil Engineering, 16(sup1), s115-s136.

Prochowski, L., (2010). “Analysis of displacement of a concrete barrier on impact of a vehicle. theoretical model and experimental validation." Journal of KONES, 17(4), 399-406.

Pulson, P. S., (1994) "Structures under shock and impact III." Southampton, UK: WIT Press.

Rao, C. L., Narayanamurthy, V. and Simha, K., (2016). "Applied impact mechanics." West Sussex, UK: John Wiley \& Sons.

Ren, F., Mattus, C. H., Wang, J. J. -A. and DiPaolo, B. P., (2013). "Effect of projectile impact and penetration on the phase composition and microstructure of high performance concretes." Cement and Concrete Composites, 41, 1-8.

Roybal, R., Tlomak, P., Stein, C. and Stokes, H., (1999). "Simulated space debris impact experiments on toughened laminated thin solar cell cover glass." International Journal of Impact Engineering, 23(1, Part 2), 811-821.

Sakai, Y., Nakatani, M., Takeuchi, A., Omorai, Y. and Kishi, T., (2016). "Mechanical behavior of cement paste and alterations of hydrates under high-pressure triaxial testing." Journal of Advanced Concrete Technology, 14(1), 1-12.

Shiu, W., Donze, F. -V. and Daudeville, L., (2008). "Compaction process in concrete during missile impact: a DEM analysis." Computers and Concrete, 5(4), 329-342.

Song, W., Lv, Y., Li, J., Wang, C. and Ning, J., (2016). "Influence of impact conditions on plasma generation during hypervelocity impact by aluminum projectile." Physics of Plasmas, 23(7), 073506.

Suda, Y., Kono, I., Saito, T. and Saeki, T., (2017). "Evaluation for air mass trasport of hardend cement paste drying various humidity by pore structure and hydration product." Cement Science and Concrete Technology, 71(1), 210-217. 
Togami, K., Hashimoto, T. and Takayama, K., (2004). "Hypervelocity flow research in ballistic range." In: I. Grant Ed. Proc. 24 $4^{\text {th }}$ International Congresss of Aeronautical Sciences, Yokohama, Japan 29 August 3 September 2004. Edinburgh, UK: Optimage Ltd.,16-26.

Tsang, H. -H. and Lam, N., (2008). "Collapse of reinforced concrete column by vehicle impact." Computer-Aided Civil and Infrastructure Engineering, 23, 427-436.

Vernon-Parry, K. D., (2000). "Scanning electron microscopy: an introduction." III-Vs Review, 13(4), 40-44.

Vossoughi, F., Ostertag, C. P., Monteiro, P. J. M. and Johnson, G. C., (2007). "Resistance of concrete protected by fabric to projectile impact." Cement and Concrete Research, 37(1), 96-106.
Vu, X. H., Daudeville, L. and Malecot, Y., (2011). "Effect of coarse aggregate size and cement paste volume on concrete behavior under high triaxial compression loading." Construction and Building Materials, 25(10), 3941-3949.

Vu, X. H., Malecot, Y., Daudeville, L. and Buzaud, E., (2009). "Experimental analysis of concrete behavior under high confinement: effect of the saturation ratio." International Journal of Solids and Structures, 46(5), 1105-1120.

Wegener, M., Sutcliffe, M. and Morgan, R., (2000). "Optical study of a light diaphragm rupture process in an expansion tube." Shock Waves, 10(3), 167-178.

Zhang, J. and Scherer, G. W., (2011). "Comparison of methods for arresting hydration of cement." Cement and Concrete Research, 41(10), 1024-1036. 